\title{
Stability of lysozyme incorporated into electrospun fibrous mats for wound healing
}

Liu, Xiaoli; Nielsen, Line Hagner; Qu, Haiyan; Christensen, Lars Porskjær; Rantanen, Jukka; Yang, Mingshi

\section{Published in:}

European Journal of Pharmaceutics and Biopharmaceutics

Link to article, DOI:

10.1016/j.ejpb.2019.01.003

Publication date:

2019

Document Version

Peer reviewed version

Link back to DTU Orbit

Citation (APA):

Liu, X., Nielsen, L. H., Qu, H., Christensen, L. P., Rantanen, J., \& Yang, M. (2019). Stability of lysozyme incorporated into electrospun fibrous mats for wound healing. European Journal of Pharmaceutics and Biopharmaceutics, 136, 240-249. https://doi.org/10.1016/j.ejpb.2019.01.003

\section{General rights}

Copyright and moral rights for the publications made accessible in the public portal are retained by the authors and/or other copyright owners and it is a condition of accessing publications that users recognise and abide by the legal requirements associated with these rights.

- Users may download and print one copy of any publication from the public portal for the purpose of private study or research.

- You may not further distribute the material or use it for any profit-making activity or commercial gain

- You may freely distribute the URL identifying the publication in the public portal 


\section{Accepted Manuscript}

Research paper

Inropean

lournal of

Pharmaceuties and

Biepharmaceutics

Stability of lysozyme incorporated into electrospun fibrous mats for wound healing

Xiaoli Liu, Line Hagner Nielsen, Haiyan Qu, Lars Porskjær Christensen, Jukka Rantanen, Mingshi Yang

PII: S0939-6411(18)30705-7

DOI: https://doi.org/10.1016/j.ejpb.2019.01.003

Reference: EJPB 12952

To appear in: European Journal of Pharmaceutics and Biopharmaceutics

Received Date: 3 June 2018

Revised Date:

9 November 2018

Accepted Date:

6 January 2019

Please cite this article as: X. Liu, L. Hagner Nielsen, H. Qu, L. Porskjær Christensen, J. Rantanen, M. Yang, Stability of lysozyme incorporated into electrospun fibrous mats for wound healing, European Journal of Pharmaceutics and Biopharmaceutics (2019), doi: https://doi.org/10.1016/j.ejpb.2019.01.003

This is a PDF file of an unedited manuscript that has been accepted for publication. As a service to our customers we are providing this early version of the manuscript. The manuscript will undergo copyediting, typesetting, and review of the resulting proof before it is published in its final form. Please note that during the production process errors may be discovered which could affect the content, and all legal disclaimers that apply to the journal pertain. 


\title{
Stability of lysozyme incorporated into electrospun fibrous mats for wound healing
}

Xiaoli Liu ${ }^{1}$, Line Hagner Nielsen ${ }^{2}$, Haiyan $\mathrm{Qu}^{3}$, Lars Porskjær Christensen ${ }^{3,4}$, Jukka Rantanen ${ }^{1}$, Mingshi Yang*1,5

${ }^{1}$ Department of Pharmacy, University of Copenhagen, Universitetsparken 2, DK-2100 Copenhagen, Denmark

${ }^{2}$ Department of Micro- and Nanotechnology, Technical University of Denmark, Ørsteds Plads 345C, DK-2800 Kgs. Lyngby, Denmark

${ }^{3}$ Department of Chemical Engineering, Biotechnology and Environmental Technology, University of Southern Denmark, Campusvej 55, DK-5230 Odense M, Denmark

${ }^{4}$ Department of Chemistry and Bioscience, The Faculty of Engineering and Science, Aalborg University, Fredrik Bajers Vej 7H, DK-9220 Aalborg Ø, Denmark

${ }^{5}$ Wuya College of Innovation, Shenyang Pharmaceutical University, Wenhua Road No. 103, 110016 Shenyang, China

"Corresponding author: Mingshi Yang (mingshi.yang@sund.ku.dk)

\begin{abstract}
In this study, we investigated the feasibility of incorporating protein drugs into electrospun fibrous mats (EFMs) for wound healing using lysozyme as a model drug. Lysozyme nanoparticles (LysoNPs) were first obtained by electrospray. Lysozyme solutions were prepared with a binary solvent mixture of ethanol $(\mathrm{EtOH})$-water $\left(\mathrm{H}_{2} \mathrm{O}\right)$ at varied volume ratios. Subsequently, Lyso-NPs were suspended in poly(lactic-co-glycolic acid) (PLGA) solutions using trifluoroethanol (TFE) as a solvent. Lyso-NPs loaded EFMs were obtained by electrospinning of the aforementioned suspensions, and the bioactivity of lysozyme in the EFMs was investigated using fluorescence-based assay kit. The electrosprayed Lyso-NPs were spherical with barely altered bioactivity as compared to the untreated raw material when using EtOH- $\mathrm{H}_{2} \mathrm{O}(30: 70$, v/v) as solvent. After the subsequent electrospinning process, more than $90 \%$ of the bioactivity of lysozyme was retained compared to the raw material. The cytotoxicity of the produced EFMs was evaluated by thiazolyl blue tetrazolium bromide (MTT) study and the proliferation and distribution of mouse fibroblast cells (L929) growing on EFMs were investigated using 4,6-diamidino-2-phenylindol dihydrochloride (DAPI) for nucleic acid staining.
\end{abstract}


Nearly negligible cytotoxicity of all the EFMs was observed according to the MTT study. Furthermore, it was observed that the L929 cells grew well on the Lyso-EFMs, especially those with the modification of polyethylene glycol (PEG) that was added to improve the hydrophilicity of EFMs. This study demonstrated that the electrospray/electrospinning processes are suitable for loading biomacromolecules to produce functionalized wound dressings to promote wound healing.

Key words: protein, bioactivity, electrospray, electrospinning, cell growth, cytotoxicity

\section{Introduction}

Wound dressings are expected to provide physical barriers to protect the wound area. Moreover, these should also mimic the extracellular matrix (ECM) providing adequate mechanical and structure support for cell attachment, proliferation and differentiation and thus, promoting the healing process of deep wounds and ulcers (1-4). In the recent years, wound dressings functionalized with biomacromolecules have been extensively investigated for wound healing. It has been reported that by formulating biomacromolecules, such as growth factors, into the dressing materials, wound healing could be promoted (5-7). The biological signals can actively guide and direct cell functions $(5,8,9)$, however, the growth factors are usually unstable in vivo and can diffuse rapidly out from the target site due to exudates secretion around the wound area $(10,11)$. Therefore, the injection of growth factors directly to the wound site is ineffective due to their short half-life. In order to reach high efficiency of biological effects of growth factors, a functionalized wound dressing with a controlled drug release profile is needed to promote wound healing.

Currently, electrospun fibrous mats (EFMs) are normally employed to deliver biomacromolecules locally to the target wound area $(6,12-14)$. For successful application of a drug delivery system loaded with biomacromolecules, two critical aspects need to be taken into account; the stability of the incorporated biomacromolecules and the release profile. The biomacromolecules can be protected from chemical, physical or enzymatic degradation processes after being incorporated into the release carriers (15). However, the bioactivity of the biomacromolecules might be lost due to the denaturation and deactivation during the formulating and manufacturing processes (16, 17). Besides these procedures, the stability of biomacromolecules within the EFMs during storage and in vivo release should also be taken into consideration $(18,19)$.

So far, various strategies such as physical adsorption (20), blend electrospinning and co-axial 
electrospinning (21-24) and covalent immobilization on the surface of EFMs (25-27) have been developed to prepare functionalized EFMs with biomacromolecules. The method using physical adsorption is the easiest way and the bioactivity of biomacromolecules can be well preserved, although the applications are limited due to uncontrolled release profiles (28). Controlled release of biomacromolecules can be achieved by blend electrospinning or co-axial electrospinning. Normally, suspensions or emulsions are prepared prior to the fabricating process, where aqueous solutions of biomacromolecules are suspended or emulsified in polymer solutions made of an organic solvent. In a co-axial electrospinning process, a solution of biomacromolecules and a solution of polymers are electrospun from different feeding channels. As frequently reported, the challenge for both blend electrospinning and co-axial electrospinning is to maintain the bioactivity of the biomacromolecules $(16,29)$. A previous study showed that the bioactivity of alkaline phosphatase decreased dramatically after either blend electrospinning or co-axial electrospinning, and less than $50 \%$ of the bioactivity remained as compared to the untreated raw material (16). The bioactivity of biomacromolecules is also a problem for covalent immobilization, where it might be affected by the process of covalent conjugation, and also inactivated after exposing in the harsh environment in vivo (30).

In this study, lysozyme was used as a model protein drug because it is easy to obtain and the analytical methods to characterize its stability have been well reported in literature $(31,32)$. PLGA is a safe material which has been approved by FDA and widely used in pharmaceutical application with controllable drug release behavior. It was used as the EFMs forming material in this study because its application in the field of wound dressing has recently attracted more and more attention $(33,34)$. However, its potential in the wound healing application has far been fully investigated. As for PEG, it was selected because it is hydrophilic, and it was reported that PEG could stabilize protein structure and protect lysozyme from denaturation while using organic solvent in the EFMs fabrication process (16). In addition, it was reported that the release behaviors of lysozyme can be modified as improving the hydrophilicity of EFMs $(23,33)$. Herein, fabrication of lysozyme loaded EFMs with a focus on the bioactivity of lysozyme after electrospray/electrospinning and the chemical stability of lysozyme during the release study were evaluated in this study.

\section{Materials and Methods}

\subsection{Materials}

PLGA (LA: GA, 50:50, molar ratio) with inherent viscosity $\left(25^{\circ} \mathrm{C}, 0.1 \%\right.$ chloroform [CHL]) in the range of 0.61-0.74 dl/g was purchased from Evonik (Darmstadt, Germany). Lysozyme (from 
chicken egg white), molecular biology grade of trifluoroethanol (TFE), ethanol (EtOH), acetonitrile, trifluoroacetic acid (TFA), Tween-20, molecular biology grade of paraformaldehyde, 4,6Diamidino-2-phenylindole dihydrochloride (DAPI), Triton-X100, poly(ethylene oxide) (PEG Mw 20,000), thiazolyl blue tetrazolium bromide (MTT) and phosphate buffered saline (PBS) tablets were all obtained from Sigma-Aldrich (Brøndby, Denmark). Mouse fibroblast cell (L929) was acquired from ATCC (Wesel, Germany), and the cell culture medium Dulbecco's Modified Eagle's Medium (DMEM) and penicillin-streptomycin (PS) were obtained from Sigma-Aldrich (Brøndby, Denmark). Fetal bovine serum (FBS) was acquired from Biowest (MO, USA). All materials were used as obtained.

\subsection{Preparation of EFMs}

The molecular weight of PLGA used in this study was measured using a size exclusion chromatography, which has been reported in a previous study, i.e. Mw 67,900 kDa. (35). The PLGA was dissolved in TFE at a concentration of $30 \%(\mathrm{w} / \mathrm{v})$. The electrospinning setup included a syringe pump (Harvard Apparatus, Holliston, MA, USA) and a high-voltage supply (maximum of 20kV, PS/FC20R06, Glassman High Voltage Inc., High Bridge, NJ, USA). The samples were collected on a rotating drum with the speed of $500 \mathrm{rpm} / \mathrm{min}$ at room temperature (RT) and ambient humidity. A 16 gauge needle (inner diameter $1.19 \mathrm{~mm}$ and outer diameter $1.65 \mathrm{~mm}$ ) and $10 \mu \mathrm{L} / \mathrm{min}$ flow rate were used, and the distance between the nozzle tip to the grounded collector was $10 \mathrm{~cm}$. The voltage was adjusted to get a stable cone-jet with a minimum change of approximately $9 \mathrm{kV}$.

\subsection{Preparation of lysozyme loaded EFMs}

$2 \%(\mathrm{w} / \mathrm{v})$ lysozyme was dissolved in a binary solvent mixture of $\mathrm{EtOH}-\mathrm{H}_{2} \mathrm{O}$ at different volume ratios of 20:80, 30:70, 40:60, or 80:20 (EtOH: $\mathrm{H}_{2} \mathrm{O}$, v/v). Lyso- NPs were prepared by electrospray using the same setup as for preparing EFMs described in section 2.2. A 27 gauge needle (Chip Quik Inc., Niagara Falls, NY, USA) was used. The flow rate was $3 \mu \mathrm{L} / \mathrm{min}$, and the distance between the nozzle tip to grounded collector was $4 \mathrm{~cm}$. The electrosprayed Lyso-NPs were collected and dried in a vacuum oven overnight. Lyso-NPs were dispersed into the PLGA polymer solutions and mixed well at varied mass ratios (i.e. 1:100, 2.5:100 or 5:100, Lyso: PLGA, w/w) before electrospinning. PEG was added together with Lyso-NPs to modify the lysozyme release behavior at varied mass ratios, i.e. 1:100, 5:100, 10:100, and 20:100 (PEG: PLGA, w/w). All the processing parameters for preparing Lyso-EFMs were the same as used for preparing EFMs as described in section 2.2. 


\subsection{Biological activity of the incorporated lysozyme in EFMs}

The bioactivity of Lyso-NPs prepared by electrospray was evaluated using a fluorescence-based EnzChek ${ }^{\circledR}$ Lysozyme Assay Kit (Molecular Probes, Eugene, OR, USA). Evaluation of the bioactivity of Lyso-NPs prepared from different formulations was used to find the formulation with the best biological activity, which will be used for further electrospinning. In order to evaluate the bioactivity of Lyso-NPs after being electrospun, the samples were prepared under the same conditions as aforementioned in section 2.2, except that no PLGA polymer was added in the electrospinning solutions. In this study, the collected beads (not fibers) (ES-(Lyso-NPs)) were dried in a vacuum oven and then dissolved in $\mathrm{H}_{2} \mathrm{O}$ to evaluate its biological activity using the Lysozyme Assay Kit. Freshly dissolved lysozyme (raw material) served as a control for $100 \%$ bioactivity.

\subsection{Morphology of EFMs}

The morphology of the prepared EFMs was characterized using scanning electron microscope (SEM, Hitachi High-Tech HITACHI, Tokyo, Japan). The samples were mounted on metal stubs with doublesided adhesive tape and coated under vacuum with gold in an argon atmosphere prior to observation. The specimens were then imaged at an accelerating voltage of $5 \mathrm{kV}$.

\subsection{Water contact angle (WCA) of the EFMs}

For evaluation of the hydrophilicity of the obtained EFMs, WCAs were measured using pendant drop analyzer (KRÜSS GmbH, Hamburg, Germany). A drop of water $(20 \mu \mathrm{L})$ was added on the surface of the EFMs, and measurements were acquired at 0,30 min, and $1 \mathrm{~h}$ to observe the change of WCA over time. Each specimen was measured in triplicate.

\subsection{Mechanical property}

The mechanical properties of the resulted EFMs were carried out using dynamic mechanical analysis instrument (DMA Q800, TA instruments, New Castle, DE, USA). All the samples were cut into a specific rectangular shape, with a width fixed at $2 \mathrm{~mm}$ cut by the tools provided by TA instruments and the length (approximately $1 \mathrm{~cm}$ ) of the EFMs was detected by the DMA instrument software (DMA Q800). The thickness of the mats was exactly measured by the electronic micrometer (Schut Geometrical Metrology, Netherland). The mechanical properties of the EFMs were studied at RT with a ramp displacement of $100 \mu \mathrm{m} / \mathrm{min}$ in a DMA strain rate mode. Each specimen was measured in triplicate. 


\subsection{In vitro release of lysozyme from EFMs}

The Lyso-EFMs were cut into small squares $(2 \times 2 \mathrm{~cm})$ for the in vitro release study. The release study was performed in TPBS medium $(0.1 \mathrm{v} / \mathrm{v} \%$ Tween-20 in $0.01 \mathrm{M}$ PBS at pH 7.4) in $2.0 \mathrm{~mL}$ Eppendorf tube. Samples were incubated in a water bath with a shaking speed of $100 \mathrm{rpm}$ either at $37^{\circ} \mathrm{C}$ or at RT. Initially, $1 \mathrm{~mL}$ of TPBS was added to immerse the fibrous mats, and subsequently, $200 \mu \mathrm{L}$ medium was taken out at designated time intervals $(0.5,1,2,4$, and $24 \mathrm{~h})$ and $200 \mu \mathrm{L}$ fresh TPBS was added to maintain the volume. Thereafter, at 2, 4 and 7 days, and similarly every week until 56 days, a sample was taken out and the release medium was replaced with $1 \mathrm{~mL}$ fresh TPBS medium. The Eppendorf tube was sealed with parafilm to prevent the evaporation of the release medium during the release study.

The lysozyme concentration in the collected supernatant was analyzed by high performance liquid chromatography (HPLC) (1260 Infinity, Agilent Technologies, Santa Clara, CA, USA) using a reversed phase C18 column (300A, Phenomenex Aps, Værløse, Denmark) at $280 \mathrm{~nm}$. The mobile phases consisted of phase A: acetonitrile/0.1\% (v/v) TFA and phase $\mathrm{B}: \mathrm{H}_{2} \mathrm{O} / 0.1 \%$ (v/v) TFA. The gradient elution started from $32 \%(\mathrm{v} / \mathrm{v})$ of phase A to $60 \%(\mathrm{v} / \mathrm{v})$ of phase A over 10 min and return to the starting phase ratio within further $5 \mathrm{~min}$ at a flow rate of $1 \mathrm{~mL} / \mathrm{min}$. The release study was performed in triplicate, and the results were presented as cumulative release as a function of time.

\subsection{Chemical analysis of remained lysozyme in EFMs after release study}

At the end of release study, lysozyme residue inside EFMs was characterized using a previously reported method (36). Briefly, Lyso-EFMs was dissolved in TFE and centrifuged. Polymer solution was removed and the precipitated protein pellet was washed with TFE for 2 times. The protein pallet was reconstituted in $1 \mathrm{~mL}$ TPBS at $37^{\circ} \mathrm{C}$ for $1 \mathrm{~h}$ to determine the soluble residue in EFMs. Any remaining precipitate was reconstituted in $1 \mathrm{~mL}$ denaturing solution (TPBS/6M urea/ $1 \mathrm{mM}$ EDTA) and incubated at $37^{\circ} \mathrm{C}$ for $30 \mathrm{~min}$ to determine the content of any physical aggregate. If any insoluble precipitate collected after previous treatment, it will be incubated with reducing solution (TPBS/6M urea/ $1 \mathrm{mM}$ EDTA+ 10mM DL-dithiothereitol) to determine any disulfide-bonded aggregate.

\subsection{Cytotoxicity of the EFMs}

For investigating the cytotoxicity of the fabricated EFMs, the cell viability was measured using a MTT assay. Firstly, L929 cells were seeded in 96 -well plates at $37{ }^{\circ} \mathrm{C}$ and $5 \% \mathrm{CO}_{2}$ overnight at a 
density of $1 \times 10^{4}$ cells per well. EFMs were sterilized overnight using UV light followed by incubation with the pre-seeded cells. After incubation for $48 \mathrm{~h}$, the EFMs were removed from the wells, and $10 \mu \mathrm{L}$ MTT solution $(5 \mathrm{mg} / \mathrm{mL})$ was added to each well and incubated for $4 \mathrm{~h}$ at $37{ }^{\circ} \mathrm{C}$ and $5 \% \mathrm{CO}_{2}$. After $4 \mathrm{~h}$, the supernatant was discarded, and $150 \mu \mathrm{L}$ DMSO was added to terminate the reaction. The absorbance of the resultant solution was measured at $490 \mathrm{~nm}$ on a microplate reader (Varioskan LUX Multimode, Thermo Fisher Scientific, MA, USA). The cell viability was plotted as percentage of the optical density (OD) value for the control group (cells growing without addition of EFMs). The study was performed in triplicate

\subsection{Cell growth on EFMs}

For investigating the cell growth on the Lyso-EFMs, mouse fibroblast cells (L929) were utilized. EFMs $(0.8 \mathrm{~cm} \times 0.8 \mathrm{~cm})$ were sterilized using UV light overnight before adding the EFMs to a 48 well plate followed by adding L929 cells in a seeding density of $1 \times 10^{5}$ cells per well in $1 \mathrm{~mL}$ of culture medium. After incubation of the cells together with the EFMs for $48 \mathrm{~h}$ at $37{ }^{\circ} \mathrm{C}$ and $5 \% \mathrm{CO}_{2}$, the EFMs were washed three times with PBS, and then fixed with $4 \mathrm{v} / \mathrm{v} \%$ paraformaldehyde in PBS for $20 \mathrm{~min}$.

For observing the morphology of cells growing on EFMs, the samples were dried after the fixing step followed by gold coating and visualization using SEM. For monitoring cell growth, DAPI was used for staining the cell nuclear. After the fixing step, $0.1 \%$ Triton-X 100 in PBS was added for 5 min at RT for cell permeabilization, and then $1 \%$ fetal bovine serum (FBS) was used for 20 min to reduce nonspecific background staining. Subsequently, the cells were stained with DAPI (10 $\mu \mathrm{g} / \mathrm{mL}$ in PBS) for 5 min. Before each step and after the staining, the cells were washed gently three times with PBS. The stained samples were observed using fluorescence microscope (CellSens, Olympus America Inc., Center Valley, PA, USA).

\subsection{Statistical Analysis}

All the data are presented as mean \pm standard deviation (SD). Where appropriate, statistical differences are evaluated with t-test using Origin software (v9.1, academic, OriginLab, Northampton, MA, USA). P-values below 5\% ( $<$ <.05) are considered statistically significant.

\section{Results and Discussion}

3.1 Morphology of electrosprayed Lyso-NPs and EFMs 
Spherical Lyso-NPs were obtained using electrospray (Fig. 1), and it was found that the particle appearance was influenced by the solvent selection (binary mixtures of EtOH-H $2 \mathrm{O}$ ). The most homogenous particles (approximately $100 \mathrm{~nm}$ ) were electrosprayed from a lysozyme solution using EtOH-H ${ }_{2} \mathrm{O}(20: 80, \mathrm{v} / \mathrm{v})$ as solvent (Fig. 1A). With an increase in EtOH amount in the binary solvent mixture, the particle appearance became multi-dispersed with large particles (approximately 100 $400 \mathrm{~nm}$ ) (Fig. 1B-C), and with $80 \%$ (v/v) EtOH, large particles and small fragments were obtained (Fig. 1D). This size difference might be due to the difference in conductivity of EtOH and $\mathrm{H}_{2} \mathrm{O}$. Fewer charges accumulated on the particle surface when the amount of EtOH increased in the binary solvent mixture due to its reduced polarity as compared to $\mathrm{H}_{2} \mathrm{O}$. . It is known that high coulomb repulsive force was generated because of the charges accumulated on the droplet surface (37). Coulomb repulsion force drives the droplets to break into smaller droplets and thereby, resulting in reduced particle size (38). Therefore, with increasing EtOH in the binary solvent, less Coulomb repulsion was generated; hence, part of the droplets could not break up into smaller droplets before collection. Furthermore, the drying of the droplets became faster with an increase in the proportion of ethanol in the binary solvent mixture. As a result, these droplets were solidified quicker than that containing more water, which prevented them to break up into smaller droplets.

Uniform fibrous mats were obtained for all the EFMs prepared using electrospinning in this study (Supplementary Fig. S1). There was no difference between the EFMs with/without the modification of lysozyme and/or PEG. With an increase in the amount of Lyso-NPs in PLGA suspension (> 5:100, Lyso:PLGA, w/w), unstable cone-jet started to present in the electrospinning process. Therefore, lysozyme with mass ratio 2.5:100 (Lyso:PLGA) was selected for the following study.
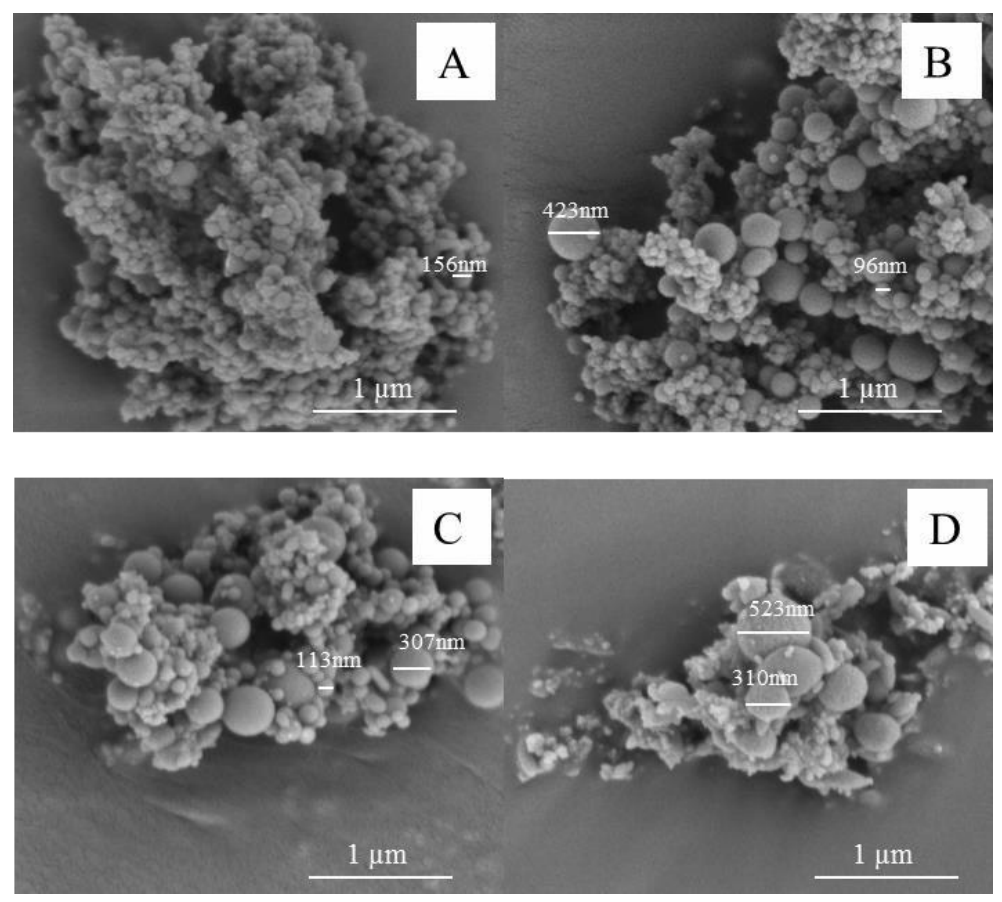
Fig. 1 SEM images of electrosprayed Lyso-NPs from binary solvents with different ratios of EtOH and $\mathrm{H}_{2} \mathrm{O}$. A: 20:80 (v/v) EtOH-H ${ }_{2} \mathrm{O} ; \mathrm{B}: 30: 70$ (v/v) EtOH- $\mathrm{H}_{2} \mathrm{O} ; \mathrm{C}: 40: 60$ (v/v) EtOH- $\mathrm{H}_{2} \mathrm{O} ; \mathrm{D}:$ 80:20 (v/v) EtOH- $\mathrm{H}_{2} \mathrm{O}$.

\subsection{Biological activity of lysozyme after electrospray and electrospinning}

The bioactivity of lysozyme was investigated for the electrosprayed Lyso-NPs. It was found that the bioactivity reduced with increasing EtOH in the binary solvent when comparing to lysozyme raw material (Fig. 2A). It might be due to that lysozyme began to aggregate with increasing EtOH in the binary solvent and thereby, the bioactivity was reduced $(39,40)$. However, the bioactivity of the Lyso-NPs prepared from EtOH- $\mathrm{H}_{2} \mathrm{O}(20: 80$, v/v) decreased more compared with the samples prepared from EtOH- $\mathrm{H}_{2} \mathrm{O} 30: 70$ and 40:60 (v/v), with a value of 78.6 $\pm 7.5 \%$. It has been reported that the charges accumulated on the surface of droplets in the electrospray process could alter protein structure conformation (17). Corresponding to the SEM results, using EtOH- $\mathrm{H}_{2} \mathrm{O}(20: 80$, v/v) as solvent, the obtained Lyso-NPs had the largest surface area compared to other samples. In addition, due to the higher conductivity of $\mathrm{H}_{2} \mathrm{O}$ compared to $\mathrm{EtOH}$, more charges could be generated on the surface of droplets when using EtOH- $\mathrm{H}_{2} \mathrm{O}(20: 80, \mathrm{v} / \mathrm{v})$ as solvent. Therefore, there is a high risk of structure deformation of the lysozyme in the Lyso-NPs prepared from EtOH- $\mathrm{H}_{2} \mathrm{O}(20: 80$, v/v). In this study, the bioactivity of Lyso-NPs prepared from EtOH- $\mathrm{H}_{2} \mathrm{O}(30: 70$, v/v) solution was $100.5 \pm 6.9 \%$ compared to the untreated lysozyme raw material, which was selected for the following electrospinning study.

It has previously been reported that using organic solvents to extract protein from hydrophobic polymer carriers to evaluate their bioactivity had a disadvantage of severely destroying protein bioactivity $(29,41)$. In order to study the bioactivity of Lyso-NPs after being electrospun, LysoNPs were electrosprayed again under the same conditions as preparing EFMs excluding PLGA. As shown in Fig. 2B, the bioactivity of Lyso-NPs retained well after further electrospray (mimicking the electrospinning process). There was no statistical difference (p-value of $0.7,0.1$ and 0.4 , respectively) for Lyso-NPs and the further electrosprayed-(Lyso-NPs) (ES-(Lyso-NPs)) with and without addition of PEG compared to untreated lysozyme raw material. It suggested that electrospray/electrospinning techniques could be used to incorporate biomacromolecules into hydrophobic polymer carriers without compromising the bioactivity. 

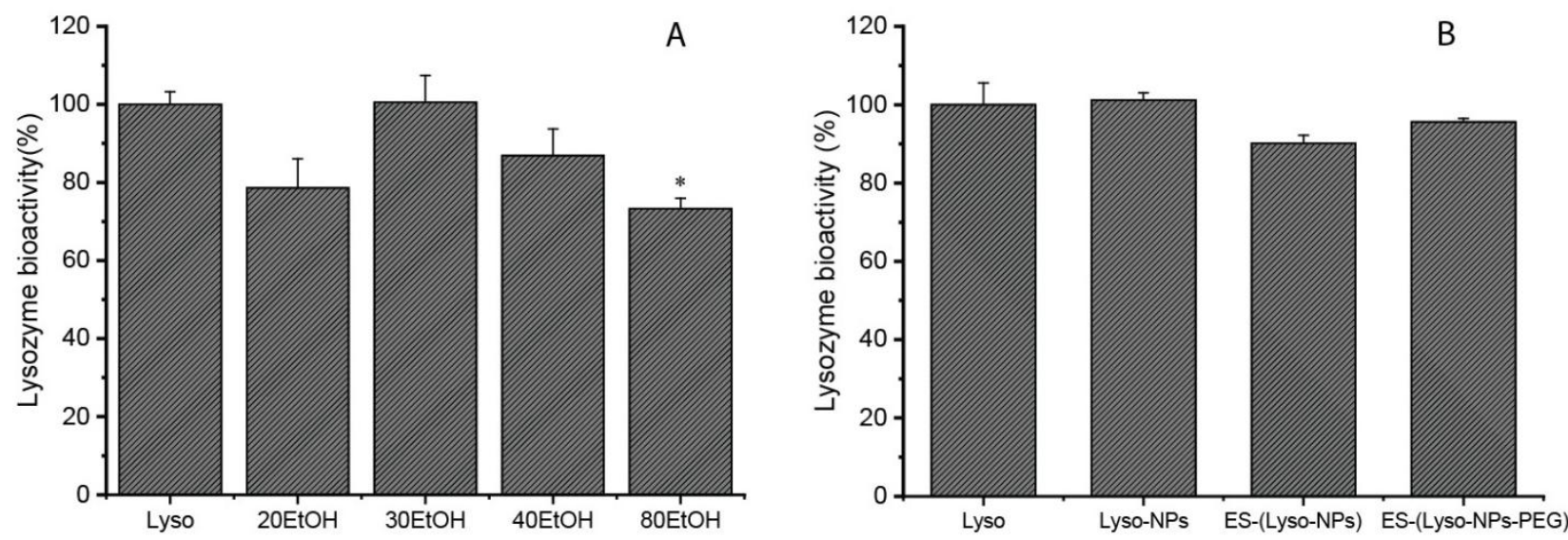

Fig. 2 Bioactivity of electrosprayed or electrospun lysozyme. A: Bioactivity of Lyso- NPs from the binary solvent EtOH-H $\mathrm{H}_{2} \mathrm{O}$ at varied volume ratios. "Lyso" refers to lysozyme raw material; "20EtOH" refers to Lyso-NPs prepared from EtOH- $\mathrm{H}_{2} \mathrm{O}\left(20: 80\right.$, EtOH: $\mathrm{H}_{2} \mathrm{O}$, v/v); B: Bioactivity of Lyso-NPs and electrosprayed-(Lyso-NPs). "Lyso-NPs" refers to lysozyme nanoparticels, "ES-(Lyso-NPs)" and "ES- (Lyso-NPs-PEG)" refer to electrosprayed-(Lyso-NPs) with and without the modification of PEG (Lysozyme: PEG, 1:1, w/w), respectively. The data represent mean $\pm \mathrm{SD}, \mathrm{n}=3$, the * indicate significant difference for $\mathrm{p}<0.05$.

\subsection{Water contact angle of the EFMs}

Hydrophilicity is an important quality attribute for wound dressings as it influences cell viability and proliferation rate (42). The images of WCA of all EFMs are showed in Fig. 3. It can be observed that the WCA decreased with an increase in the amount of lysozyme in the fibers, which indicates an improved hydrophilicity of EFMs. WCA was found to be $126 \pm 2^{\circ}$ with 1Lyso (1:100, Lyso:PLGA, w/w), whereas the addition of 2.5Lyso or $5 \operatorname{Lyso}(2.5: 100$ or 5:100, Lyso: PLGA, w/w) resulted in WCA of $124 \pm 5^{\circ}$ and $121 \pm 3^{\circ}$, respectively. WCA decreased over time due to water diffusing and penetrating into the EFMs. The addition of 10PEG (10:100, PEG:PLGA, w/w) to the EFMs decreased the WCA dramatically from $124 \pm 5^{\circ}\left(2.5\right.$ Lyso-EFM) to $42 \pm 2^{\circ}$, whereas the addition of 20 PEG (20:100, PEG:PLGA, w/w) made the EFMs so hydrophilic that the WCA was too low to be detected. 


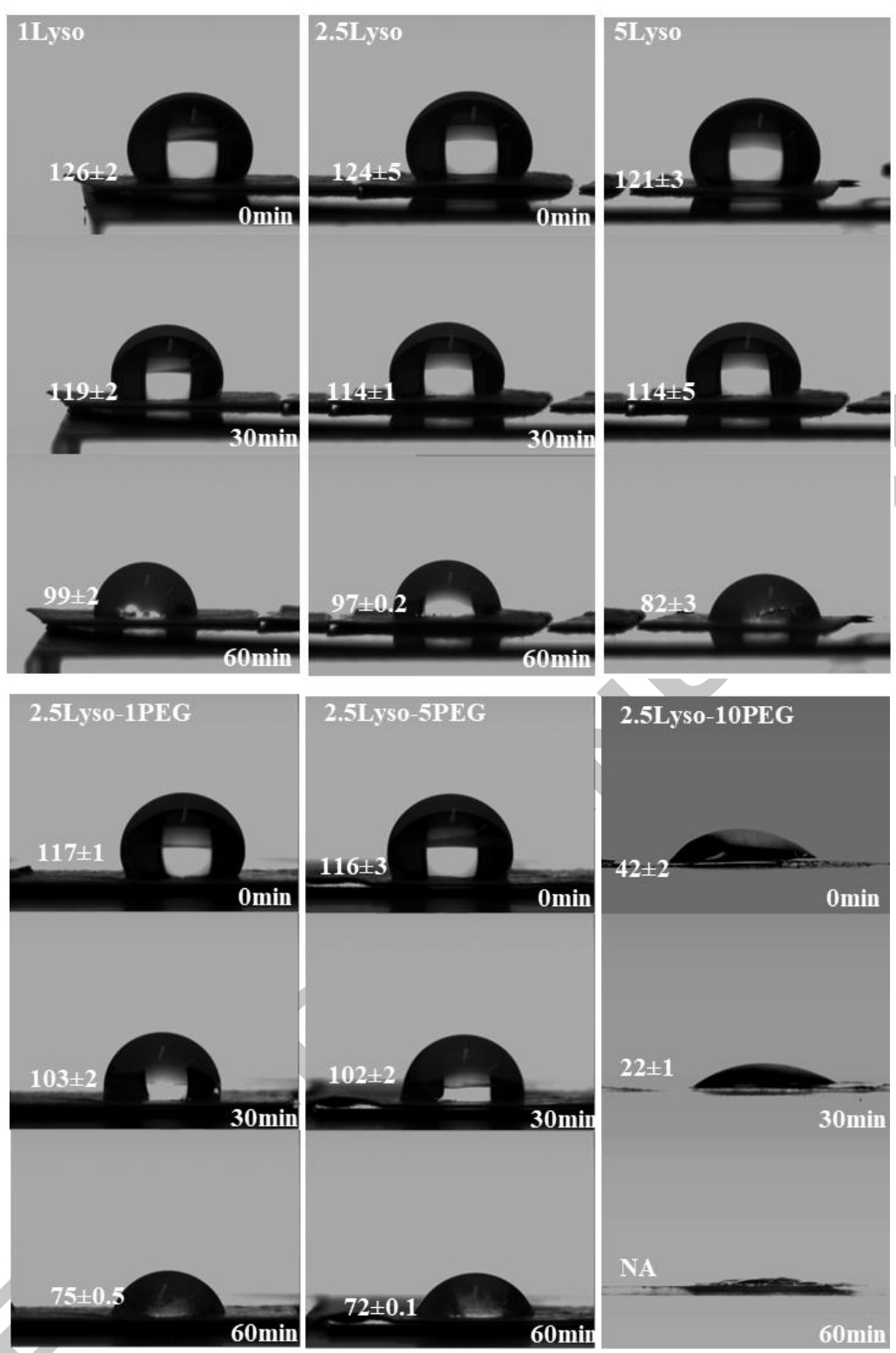

Fig. 3 Water contact angle $\left[^{\circ}\right]$ of Lyso-EFMs with and without the modification of PEG. WCA was measured at 0,30 , and $60 \mathrm{~min}$ in triplicate, and the images shown are representative for the repeated measurements (NA: Not applicable).

\subsection{Mechanical properties of EFMs}

The mechanical properties of EFMs are important as they are expected to provide physical support for wound healing, and the stress-strain curves of EFMs with and without PEG can describe the mechanical properties of the produced fibers (Fig. 4). The tensile strength and elongation rate at break decreased after adding Lyso-NPs into the EFMs (Fig. 4A). With PEG modification up to the ration of 5:100 (PEG:PLGA, w/w), the tensile strength and elongation rate at break were almost unchanged. With PEG modification that more than 10:100 (PEG:PLGA, w/w), the tensile strength of 
EFMs decreased dramatically, however, the elongation rate at break increased (Fig. 4B). The similar tendency was observed for Young's modulus of all the EFMs (Fig. 5). It was found that the Young's modulus decreased with an increase in the amount of Lyso-NPs in the EFMs. However, the Young's modulus was nearly unchanged with the addition of PEG up to 5:100 (PEG:PLGA, w/w) of mass ratio, and decreased dramatically with the addition of PEG to more than 10:100 (PEG:PLGA, w/w). This can possibly be explained by crosslinking of the polymer molecules (PEG and PLGA) being disturbed when suspending the Lyso-NPs in the PLGA solution. This tendency has previously been observed in a similar study of adding PEG into poly-lactic acid (PLA) /poly(butylene succinate) blends (43). As reported in literature, both tensile strength and Young's modulus will decrease with an increase in PEG. This is due to the fact that PEG can act as a plasticizer in EFMs, however, the elongation rate at break could increase.
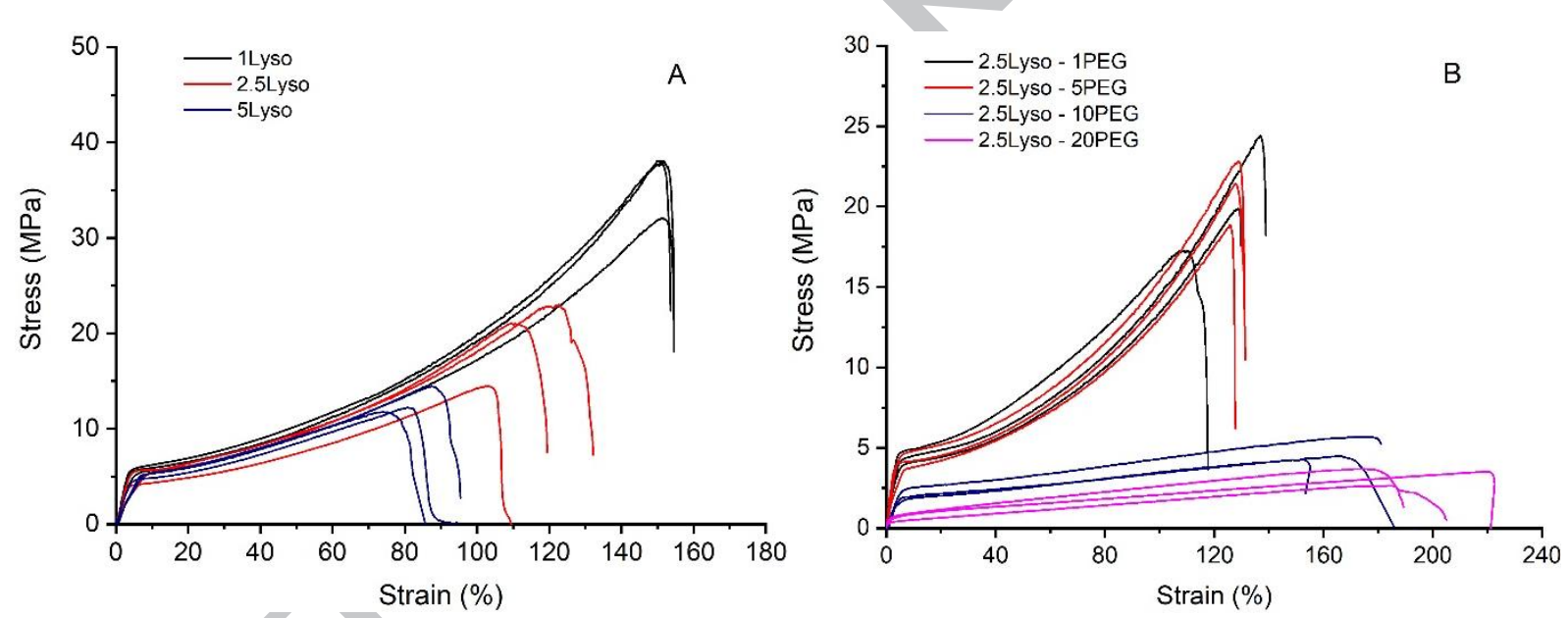

Fig. 4 Tensile strength of EFMs with and without the addition of PEG. A: Lysozyme loaded PLGAEFMs; B: Lysozyme loaded PEG/PLGA-EFMs (single measurements, n=3).

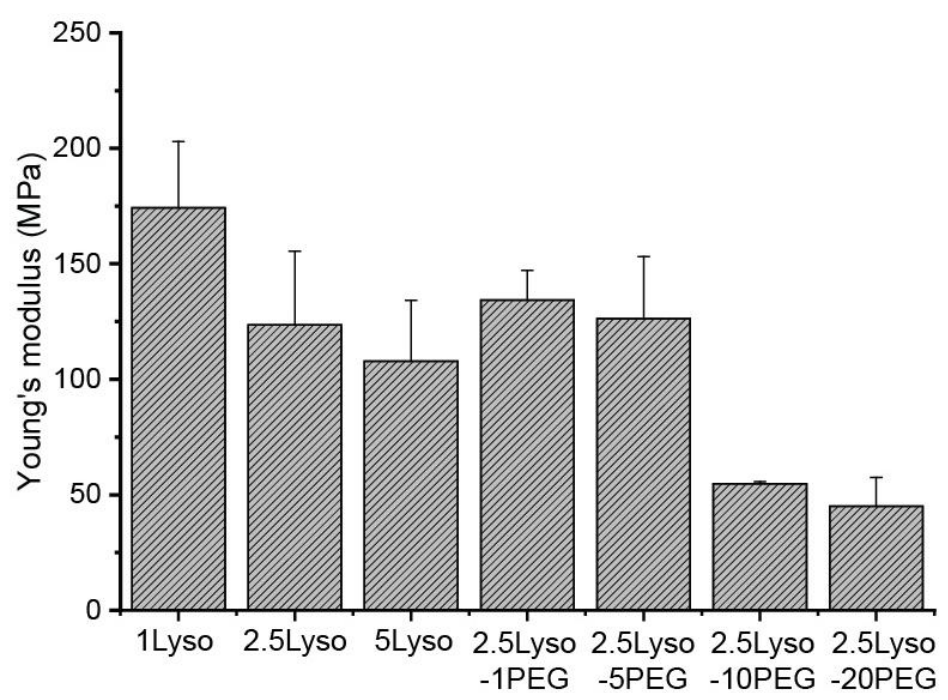


Fig. 5 Young's modulus of the Lyso-EFMs with and without the modification of PEG (mean \pm SD, $n=3$ )

It was reported that the Young's modulus and tensile strength of human skin are around 60-70 MPa and 17-21 MPa, respectively $(44,45)$. In this study, most of the EMFs had a higher Youngs's modulus and comparable tensile strength, compared to human skin, except for the ones with the PEG modification more than 10:100 (PEG:PLGA, w/w). Nevertheless, during the wound healing process, the initial epithelialization at the injured site, which performed as a temporary protection layer is only $15 \%$ tensile strength of the original skin (46). Therefore, these EFMs might be able to protect the injured site.

\subsection{In vitro lysozyme release from the EFMs}

The release of lysozyme from EFMs with PLGA was found to be limited as only 5-25 \% lysozyme was detected in the medium after 56 days (Fig. 6). An initial drug loading dependent burst release can be observed for all the samples within the first $4 \mathrm{~h}$. It might be attributed to the fact that more lysozyme accumulate on the surface of fibers during the electrospinning process contributing to the fast release. After the burst release, a plateau is present with very slow lysozyme release until the end of the release study. The plateau might be explained by the fact that the fibrous mats cannot keep their porous structure and began to merge within three weeks in TPBS at $37{ }^{\circ} \mathrm{C}$ (Fig. 7). This phenomenon will hinder the release of lysozyme from fibrous mats. After approximately 49 days, the fibrous mats began to disintegrate, resulting in a slightly increase of released lysozyme at the last time points (Fig. 6A). When comparing the release studies at different temperatures, it can be observed that more lysozyme (were) released at RT than at $37^{\circ} \mathrm{C}$ (Fig. 6B). As shown in the SEM images (Fig. 7), the fibrous mats can keep their integrity after releasing for 56 days with no merging phenomenon appeared at RT. The onset of glass transitionof PLGA is around $46{ }^{\circ} \mathrm{C}$ (Supplementary, Fig. S2 ), close to $37^{\circ} \mathrm{C}$, and therefore the polymer molecules became flexible and soft and cannot keep its rigid structure at $37^{\circ} \mathrm{C}$. This can explain the faster degradation at $37^{\circ} \mathrm{C}$.

The slow and uncompleted drug release behavior is not ideal for successful application in wound healing, and therefore, PEG was added to modify the lysozyme release behaviors. For the EFMs with PEG modification of 10:100 (PEG:PLGA, w/w), the released lysozyme was found to significantly increase from $12.0 \pm 3.1 \%$ to $16.3 \pm 1.0 \%$ at $37^{\circ} \mathrm{C}$ (p-value of 0.04 ), and at RT the release of lysozyme was found to be $24.3 \pm 1.9 \%$ (Fig. 6B). However, with PEG modification of 20:100 (PEG:PLGA, w/w), the cumulative release of lysozyme was only $13.2 \pm 2.3 \%$ at RT. This can be explained by the change of the thermodynamic properties in the physical mixture of PLGA and 
PEG $(47,48)$. In literature, it has been reported that adding PEG to PLA resulted in a decrease in $\mathrm{Tg}_{\mathrm{g}}$ due to the improved flexibility $(47,49,50)$. In this study, with an increase in PEG amount, the structure of EFM was easier to merge due to higher molecular mobility and thus, retarding the release of lysozyme.
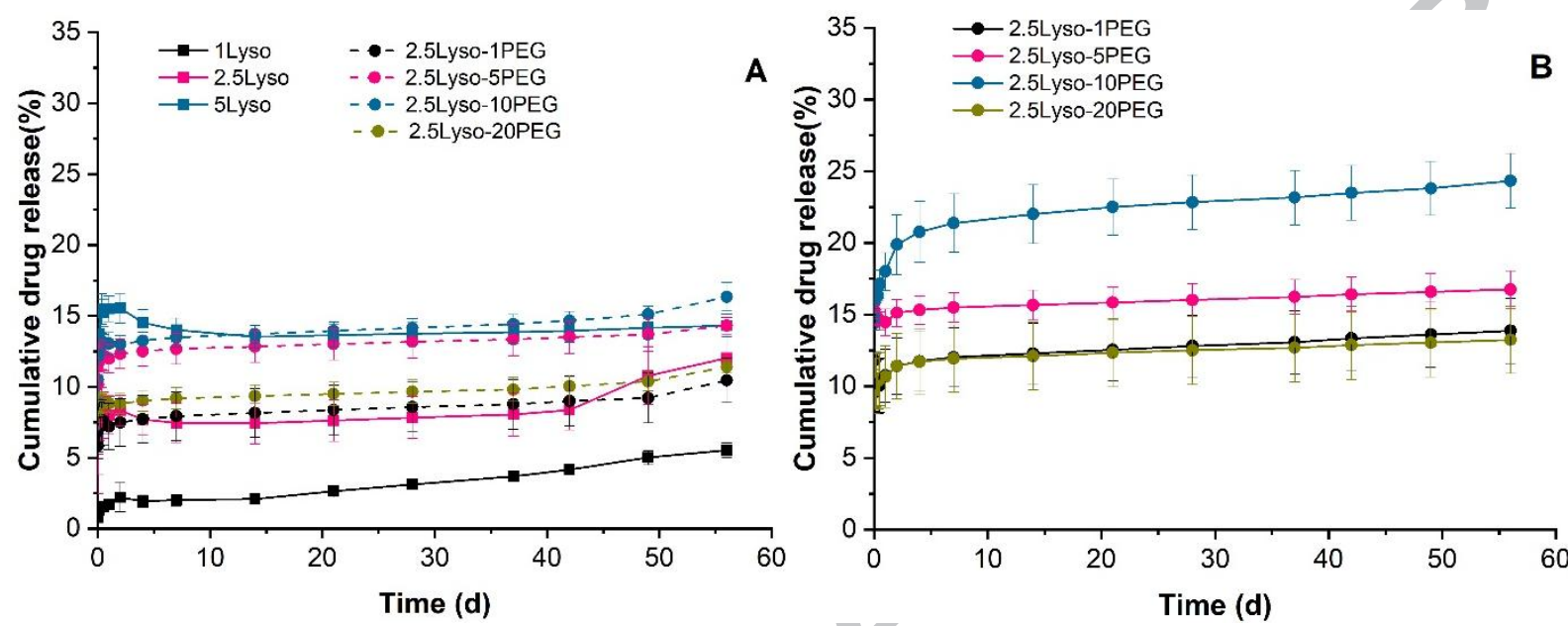

Fig. 6 Lysozyme release from the EFMs in PBS at $\mathrm{pH}$ 7.4. A: at $37^{\circ} \mathrm{C}$; B: at RT. The data represents mean $\pm \mathrm{SD}, \mathrm{n}=3$.
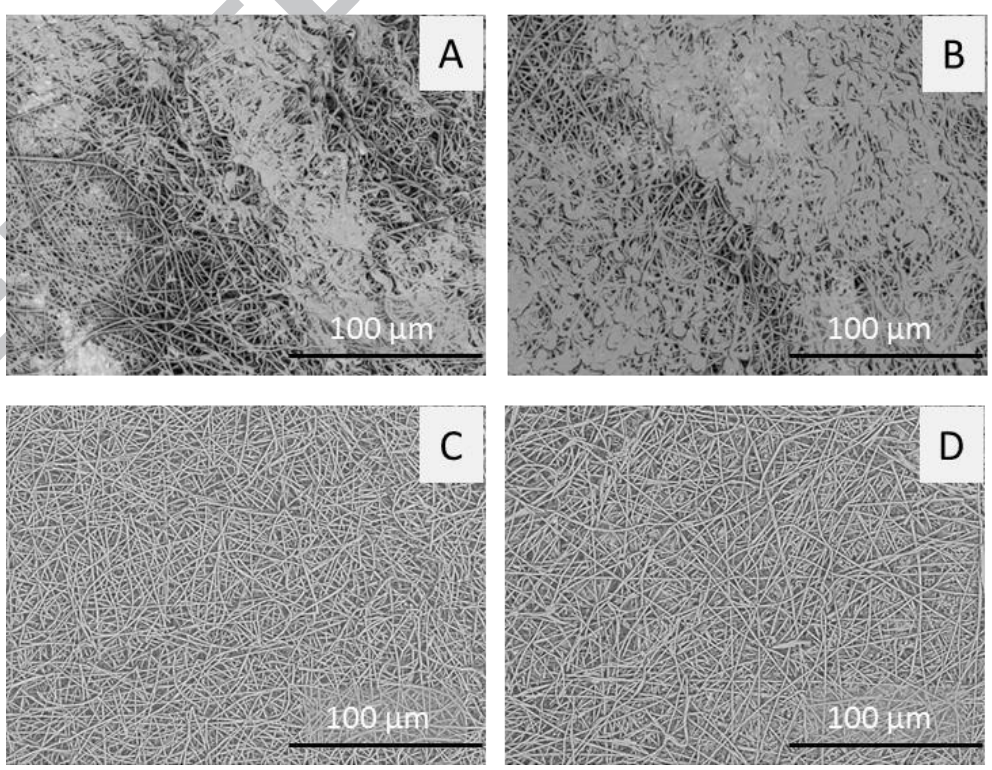

Fig. 7 SEM images of EFMs after the release study at $37{ }^{\circ} \mathrm{C}$ for 21 days and at RT for 56 days. A: 2.5Lyso-1PEG EFMs and B: 2.5Lyso-5PEG EFMs at $37^{\circ} \mathrm{C}$; C: $2.5 \mathrm{Lyso}-1 \mathrm{PEG}$ EFMs and D: 2.5Lyso 5PEG EFMs at RT.

For further investigations of the uncompleted drug release, the samples were collected and analyzed after 56 days of the release study at RT. For the unreleased lysozyme, only further $13-21 \%$ was able 
to dissolve in the release medium, hence, most of the unreleased lysozyme were insoluble aggregates with approximately 46-70 \% being physical aggregates (urea soluble) and 0.6-2 \% being disulfidebonded aggregates (dissolved in urea+ dithiothreitol) (Table 1). The total recovery of lysozyme was in the range of $84 \%$ to $110 \%$ in relation to the total amount of lysozyme loaded into EFMs. Therefore, it was found that most lysozyme was not stable and aggregated during the release study explaining the poor amount of released lysozyme.

Table 1 Lysozyme stability in PLGA EFMs during the release study over a period of 56 days.

The data represent mean $\pm \mathrm{SD}, \mathrm{n}=3$.

\begin{tabular}{lccccc}
\hline & \multicolumn{4}{c}{ Percentage of total encapsulated lysozyme (\%) } \\
\cline { 2 - 6 } Formulation & Released & Soluble & Physical & Covalent & Total \\
& & residue & aggregate & aggregate & recovery \\
\hline 2.5Lyso -1PEG & $9 \pm 2$ & $13 \pm 0.2$ & $70 \pm 13$ & $2 \pm 1$ & $93 \pm 12$ \\
2.5Lyso -5PEG & $17 \pm 1$ & $20 \pm 4$ & $46 \pm 5$ & $2 \pm 0.7$ & $84 \pm 10$ \\
2.5Lyso -10PEG & $24 \pm 2$ & $16 \pm 7$ & $68 \pm 11$ & $1 \pm 0.7$ & $110 \pm 7$ \\
2.5Lyso - 20PEG & $13 \pm 2$ & $21 \pm 4$ & $57 \pm 8$ & $0.6 \pm 0.6$ & $92 \pm 7$ \\
\hline
\end{tabular}

3.6 Cytotoxicity of the EFMs

The cytotoxicity of lysozyme loaded EFMs was evaluated using a MTT assay. The samples showed negligible cytotoxicity compared to the control group (cell growing in medium) (Fig. 8). Both PLGA and PEG are well recognized as safe materials, and are approved by FDA $(51,52)$ hence, cytotoxicity was not expected. No significant differences of the cell viability was observed for the EFMs compared to the raw material of PLGA. Therefore, the lysozyme loaded fibrous mats prepared in this study was recognized as safe for usage in the future for wound healing. 


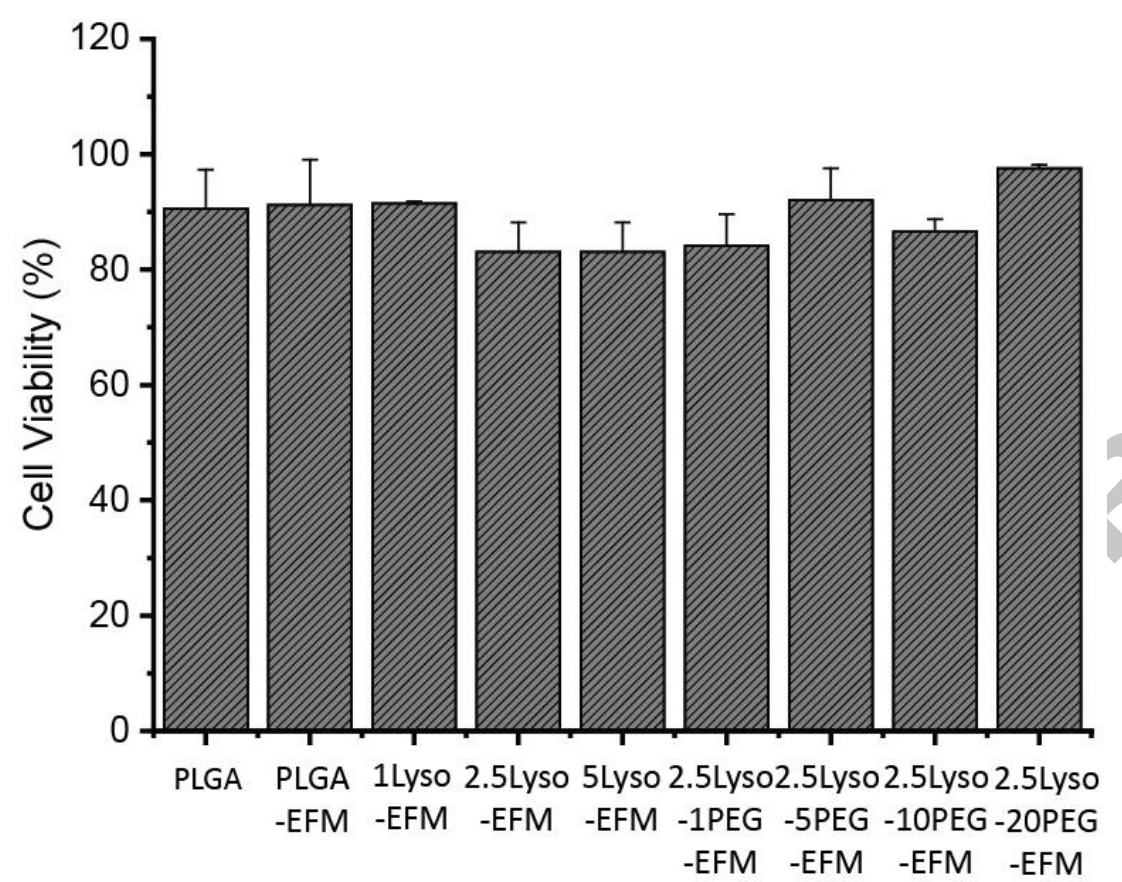

Fig. 8 L929 cell viability assessed by a MTT assay after incubation with PLGA raw materials and EFMs for 48 h. Data represent mean $\pm S D, n=3$.

\subsection{Cell growth on EFMs}

The morphology of L929 fibroblast cells growing on the Lyso-PEG/PLGA fibrous mats is presented in Fig. 9. It can be observed that the cells growing on pure PLGA EFMs were stretched and attached along the fibers, whereas the EFMs loaded with lysozyme resulted in round shaped cells and in addition they were also stretched across the interconnected fibrous structure. The cells grew on the superficial layer of 1Lyso-EFMs, and began to penetrate deeper into the fibrous mats with an increase in lysozyme loading (under fibers). The addition of PEG to the EFMs resulted in round shaped cells and they also began to penetrate into the fibrous mats with an increase in PEG amount. The size of L929 cells used in this study was approximately $10 \mu \mathrm{m}$, and it can be observed from the SEM images (Fig. 9) that the pore size was much smaller than the cells. The reason why the cells can penetrate into the deep layers of the EFMs with much smaller pore size has been interpreted previously (53). This cell penetration behavior was explained by the ability of the cells to push aside individual fibers in EFMs. If the cells can only grow on the superficial layer and form a tight layer, it will hinder the exchange of oxygen and nutrient and thus hinder wound healing process $(42)$. 


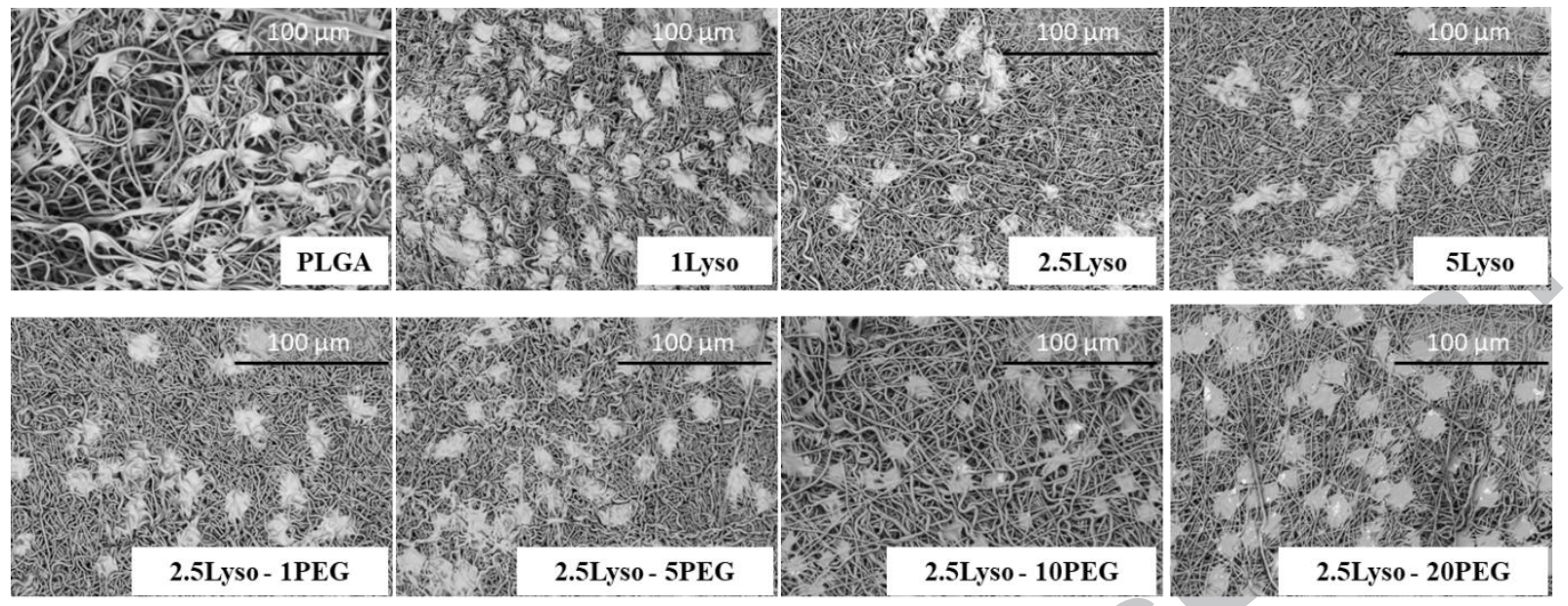

Fig. 9 SEM images of L929 cells growing on EFMs with and without addition of lysozyme and PEG. The cells were incubated with the EFMs for $48 \mathrm{~h}$ and then fixed before imaged.
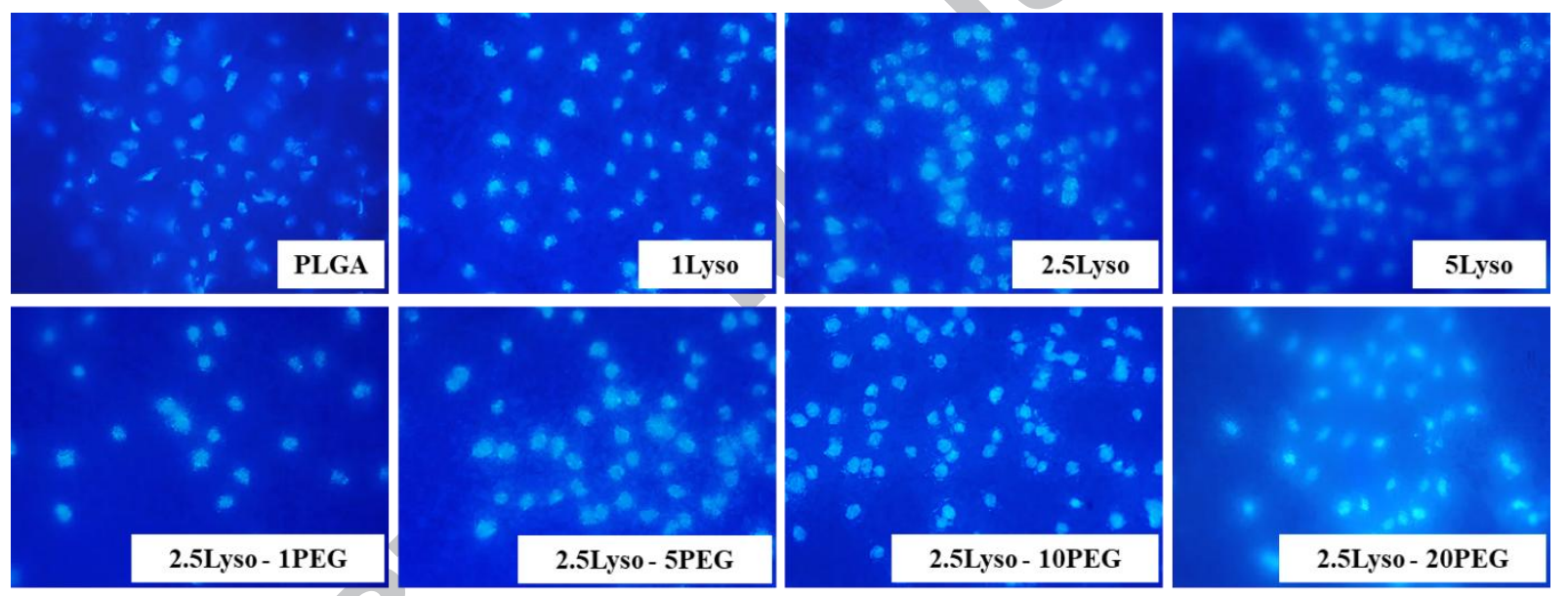

Fig. 10 Morphology of nuclei DNA of L929 cells stained with DAPI after incubation of the cells together with EFMs for $48 \mathrm{~h}$. The cells were fixed followed by staining with DAPI, and visualized using fluorescence microcopy.

The status of cells that growing on the EFMs was observed using DAPI for staining the cell nuclei (Fig. 10). Apoptotic cells were determined by the signs of change of nucleus from round and homogenous chromatin to polygonal, detached or sparse, shrinkage, condensed chromatin $(54,55)$. As observed the cells growing on pure PLGA EFMs were dead with a sign of polygonal shape (Fig. 10), which might because the PLGA EFMs were too hydrophobic for cells to attach. With an increase in loaded lysozyme, the cells were less polygonal in shape, and by the addition of PEG, the nuclei showed round and homogenous chromatin indicated good cell growth status, especially 2.5Lyso-5PEG-EFMs and 2.5Lyso -10PEG-EFMs. Both lysozyme and PEG can improve the hydrophilicity of EFMs, consequently, improving the affinity between cells and EFMs and 
facilitating cell attachment and growing.

\section{Conclusion}

Lysozyme nanoparticles loaded PLGA EFMs were prepared using electrospray/electrospinning. Negligible influence on the bioactivity of lysozyme was observed while being processed using 'protein friendly' solvents, i.e. binary solvent of $\mathrm{EtOH}-\mathrm{H}_{2} \mathrm{O}$ in this study. Electrospinning is demonstrated to be a competitive technique to fabricate biomacromolecules loaded fibrous mats with well-retained bioactivity. With an addition of PEG, the hydrophilicity of PLGA EFMs could be improved, which facilitated the proliferation of fibroblast cells (L929) on EFMs. The ability of cell compatibility and proliferation made the EFMs a potential candidate in the future for wound dressings.

\section{Acknowledgement}

This study was supported, in part, by Graduate School of Health and Medical Sciences of University of Copenhagen, Department of Pharmacy of University of Copenhagen, Department of Chemical Engineering, Biotechnology and Environmental Technology, University of Southern Denmark, the Danish Council for Independent Research, Technology and Production Sciences (FTP, Project 12- 126515/0602-02670B), and University of Copenhagen Research Centre for Control of Antibiotic Resistance (UC-CARE). Furthermore, Line Hagner Nielsen would like to thank the Danish Research Council for Technology and Production (FTP), Project DFF-400400120B for financial support. Mingshi Yang would like to thank the National Natural Science Foundation of China (grant No. 81573380), and Liaoning Province Pan Deng Xue Zhe Grant for financial support. In addition, the Denmark's Grundforsknings Fond (project DNRF122) and Villum Fondens Center for Intelligent Drug Delivery and Sensing Using Microcontainers and Nanomechanics (IDUN) is acknowledged.

\section{References}

1. Gurtner GC, Werner S, Barrandon Y, Longaker MT. Wound repair and regeneration. Nature. 2008;453(7193):314-321.

2. Vowden K, Vowden P. Wound dressings: principles and practice. Surgery (Oxford). 2014;32(9):462-467. 
3. Fonder MA, Lazarus GS, Cowan DA, Aronson-Cook B, Kohli AR, Mamelak AJ. Treating the chronic wound: a practical approach to the care of nonhealing wounds and wound care dressings. Journal of the American Academy of Dermatology. 2008;58(2):185-206.

4. Simões D, Miguel SP, Ribeiro MP, Coutinho P, Mendonça AG, Correia IJ. Recent advances on antimicrobial wound dressing: A review. European Journal of Pharmaceutics and Biopharmaceutics. 2018.

5. Ji W, Sun Y, Yang F, van den Beucken JJ, Fan M, Chen Z, Jansen JA. Bioactive electrospun scaffolds delivering growth factors and genes for tissue engineering applications. Pharm Res. 2011;28(6):1259-1272.

6. Martino MM, Briquez PS, Maruyama K, Hubbell JA. Extracellular matrix-inspired growth factor delivery systems for bone regeneration. Advanced drug delivery reviews. 2015;94:4152.

7. Wang Y, Fu C, Wu Z, Chen L, Chen X, Wei Y, Zhang P. A chitin film containing basic fibroblast growth factor with a chitin-binding domain as wound dressings. Carbohydrate polymers. 2017; 174:723-730.

8. Biondi M, Ungaro F, Quaglia F, Netti PA. Controlled drug delivery in tissue engineering. Advanced drug delivery reviews. 2008;60(2):229-242.

9. Tabata Y. The importance of drug delivery systems in tissue engineering. Pharmaceutical science \& technology today. 2000;3(3):80-89.

10. Leader B, Baca QJ, Golan DE. Protein therapeutics: a summary and pharmacological classification. Nature reviews Drug discovery. 2008;7(1):21-39.

11. Lord MS, Ellis AL, Farrugia BL, Whitelock JM, Grenett H, Li C, O'grady RL, DeCarlo AA. Perlecan and vascular endothelial growth factor-encoding DNA-loaded chitosan scaffolds promote angiogenesis and wound healing. Journal of Controlled Release. 2017;250:48-61.

12. Slaughter BV, Khurshid SS, Fisher OZ, Khademhosseini A, Peppas NA. Hydrogels in regenerative medicine. Advanced materials. 2009;21(32-33):3307-3329.

13. Rieger KA, Birch NP, Schiffman JD. Designing electrospun nanofiber mats to promote wound healing - a review. Journal of Materials Chemistry B. 2013;1(36):4531.

14. Bruggeman KF, Williams RJ, Nisbet DR. Dynamic and Responsive Growth Factor Delivery from Electrospun and Hydrogel Tissue Engineering Materials. Advanced healthcare materials. 2018;7(1):1700836.

15. Tessmar JK, Gopferich AM. Matrices and scaffolds for protein delivery in tissue engineering. Advanced drug delivery reviews. 2007;59(4-5):274-291.

16. Ji W, Yang F, Van den Beucken JJ, Bian Z, Fan M, Chen Z, Jansen JA. Fibrous scaffolds loaded with protein prepared by blend or coaxial electrospinning. Acta Biomaterialia. 2010;6(11):4199-4207.

17. Frokjaer S, Otzen DE. Protein drug stability: a formulation challenge. Nat Rev Drug Discov. 2005;4(4):298-306.

18. Estey T, Kang J, Schwendeman SP, Carpenter JF. BSA degradation under acidic conditions: a model for protein instability during release from PLGA delivery systems. Journal of pharmaceutical sciences. 2006;95(7):1626-1639.

19. Houchin M, Topp E. Chemical degradation of peptides and proteins in PLGA: a review of reactions and mechanisms. Journal of pharmaceutical sciences. 2008;97(7):2395-2404.

20. Nie H, Soh BW, Fu YC, Wang CH. Three-dimensional fibrous PLGA/HAp composite scaffold for BMP-2 delivery. Biotechnology and bioengineering. 2008;99(1):223-234.

21. Wang J, Liu J, Fan C, Mo X, He C, Chen F. Preparation of coaxial electrospinning nanofibers for nerve growth factor delivery. J Clin Rehab Tiss Eng Res. 2008;12(23):4440-4444.

22. Wu L, Li H, Li S, Li X, Yuan X, Li X, Zhang Y. Composite fibrous membranes of PLGA and chitosan prepared by coelectrospinning and coaxial electrospinning. J Biomed Mater Res A. 2010;92(2):563-574. 
23. Llorens E, Ibanez H, Del Valle LJ, Puiggali J. Biocompatibility and drug release behavior of scaffolds prepared by coaxial electrospinning of poly(butylene succinate) and polyethylene glycol. Mater Sci Eng C Mater Biol Appl. 2015;49:472-484.

24. He M, Jiang H, Wang R, Xie Y, Zhao C. Fabrication of metronidazole loaded poly ( $\varepsilon$ caprolactone)/zein core/shell nanofiber membranes via coaxial electrospinning for guided tissue regeneration. Journal of colloid and interface science. 2017;490:270-278.

25. Suk Choi J, Sang Yoo H. Electrospun nanofibers surface-modified with fluorescent proteins. Journal of Bioactive and Compatible Polymers. 2007;22(5):508-524.

26. Guex AG, Hegemann D, Giraud MN, Tevaearai HT, Popa AM, Rossi RM, Fortunato G. Covalent immobilisation of VEGF on plasma-coated electrospun scaffolds for tissue engineering applications. Colloids Surf B Biointerfaces. 2014;123:724-733.

27. Mattanavee W, Suwantong O, Puthong S, Bunaprasert T, Hoven VP, Supaphol P. Immobilization of biomolecules on the surface of electrospun polycaprolactone fibrous scaffolds for tissue engineering. ACS Appl Mater Interfaces. 2009;1(5):1076-1085.

28. Kim TG, Park TG. Surface functionalized electrospun biodegradable nanofibers for immobilization of bioactive molecules. Biotechnology progress. 2006;22(4):1108-1113.

29. Yang Y, Li X, Qi M, Zhou S, Weng J. Release pattern and structural integrity of lysozyme encapsulated in core-sheath structured poly (DL-lactide) ultrafine fibers prepared by emulsion electrospinning. European Journal of Pharmaceutics and Biopharmaceutics. 2008;69(1):106116.

30. Manning MC, Chou DK, Murphy BM, Payne RW, Katayama DS. Stability of protein pharmaceuticals: an update. Pharm Res. 2010;27(4):544-575.

31. Ji S, Thulstrup PW, Mu H, Hansen SH, van de Weert M, Rantanen J, Yang M. Effect of ethanol as a co-solvent on the aerosol performance and stability of spray-dried lysozyme. International journal of pharmaceutics. 2016;513(1-2):175-182.

32. van de Weert $M$, Haris PI, Hennink WE, Crommelin DJ. Fourier transform infrared spectrometric analysis of protein conformation: effect of sampling method and stress factors. Analytical biochemistry. 2001;297(2):160-169.

33. Liu X, Nielsen LH, Kłodzińska SN, Nielsen HM, Qu H, Christensen LP, Rantanen J, Yang M. Ciprofloxacin-loaded sodium alginate/poly (lactic-co-glycolic acid) electrospun fibrous mats for wound healing. European Journal of Pharmaceutics and Biopharmaceutics. 2018;123:4249.

34. Kim SJ, Jang DH, Park WH, Min B-M. Fabrication and characterization of 3-dimensional PLGA nanofiber/microfiber composite scaffolds. Polymer. 2010;51(6):1320-1327.

35. Liu X, Baldursdottir SG, Aho J, Qu H, Christensen LP, Rantanen J, Yang M. Electrospinnability of poly lactic-co-glycolic acid (PLGA): the role of solvent type and solvent composition. Pharmaceutical research. 2017;34(4):738-749.

36. Kang J, Lambert O, Ausborn M, Schwendeman SP. Stability of proteins encapsulated in injectable and biodegradable poly(lactide-co-glycolide)-glucose millicylinders. Int J Pharm. 2008;357(1-2):235-243.

37. Tang K, Gomez A. Monodisperse electrosprays of low electric conductivity liquids in the cone-jet mode. Journal of colloid and interface science. 1996;184(2):500-511.

38. Chakraborty S, Liao IC, Adler A, Leong KW. Electrohydrodynamics: A facile technique to fabricate drug delivery systems. Advanced drug delivery reviews. 2009;61(12):1043-1054.

39. Szymańska A, Hornowski T, Ślósarek G. Denaturation and aggregation of lysozyme in waterethanol solution. Acta Biochimica Polonica. 2012;59(2).

40. Yoshizawa S, Arakawa T, Shiraki K. Dependence of ethanol effects on protein charges. International journal of biological macromolecules. 2014;68:169-172.

41. Zhang Y, Wang X, Feng Y, Li J, Lim C, Ramakrishna S. Coaxial electrospinning of (fluorescein isothiocyanate-conjugated bovine serum albumin)-encapsulated poly ( $\varepsilon$ - 
caprolactone) nanofibers for sustained release. Biomacromolecules. 2006;7(4):1049-1057.

42. Prabaharan M, Jayakumar R, Nair S. Biomedical applications of polymeric nanofibers. In.: Springer; 2012.

43. Pivsa-Art W, Fujii K, Nomura K, Aso Y, Ohara H, Yamane H. The effect of poly(ethylene glycol) as plasticizer in blends of poly(lactic acid) and poly(butylene succinate). Journal of Applied Polymer Science. 2016;133(8):n/a-n/a.

44. Gallagher A, Ní Annaidh A, Bruyère K. Dynamic tensile properties of human skin. In.IRCOBI Conference 2012, 12-14 September 2012, Dublin (Ireland): International Research Council on the Biomechanics of Injury; 2012.

45. Pawlaczyk M, Lelonkiewicz M, Wieczorowski M. Age-dependent biomechanical properties of the skin. Postepy Dermatol Alergol. 2013;30(5):302306.

46. Semer NB, ADLER-LAVAN M. Practical plastic surgery for nonsurgeons: Hanley \& Belfus Philadelphia; 2001.

47. Essa S, Rabanel JM, Hildgen P. Effect of polyethylene glycol (PEG) chain organization on the physicochemical properties of poly (D, L-lactide)(PLA) based nanoparticles. European journal of pharmaceutics and biopharmaceutics. 2010;75(2):96-106.

48. Merino S, Brauge L, Caminade AM, Majoral JP, Taton D, Gnanou Y. Synthesis and Characterization of Linear, Hyperbranched, and Dendrimer-Like Polymers Constituted of the Same Repeating Unit. Chemistry-A European Journal. 2001;7(14):3095-3105.

49. Kulinski Z, Piorkowska E, Gadzinowska K, Stasiak M. Plasticization of poly (L-lactide) with poly (propylene glycol). Biomacromolecules. 2006;7(7):2128-2135.

50. Piorkowska E, Kulinski Z, Galeski A, Masirek R. Plasticization of semicrystalline poly (Llactide) with poly (propylene glycol). Polymer. 2006;47(20):7178-7188.

51. Makadia HK, Siegel SJ. Poly Lactic-co-Glycolic Acid (PLGA) as Biodegradable Controlled Drug Delivery Carrier. Polymers. 2011;3(3):1377-1397.

52. Jones D. Pharmaceutical applications of polymers for drug delivery: iSmithers Rapra Publishing; 2004.

53. Boland ED, Telemeco TA, Simpson DG, Wnek GE, Bowlin GL. Utilizing acid pretreatment and electrospinning to improve biocompatibility of poly (glycolic acid) for tissue engineering. Journal of Biomedical Materials Research Part B: Applied Biomaterials. 2004;71(1):144-152.

54. Wang F, Wang Y-H, Wang J-J, Xu H-L, Wang C-M. Eriodictyol-induced anti-cancer and apoptotic effects in human hepatocellular carcinoma cells are associated with cell cycle arrest and modulation of apoptosis-related proteins. Bangladesh Journal of Pharmacology. 2016;11(2):285-291.

55. Deepa M, Sureshkumar T, Satheeshkumar PK, Priya S. Antioxidant rich Morus alba leaf extract induces apoptosis in human colon and breast cancer cells by the downregulation of nitric oxide produced by inducible nitric oxide synthase. Nutrition and cancer. 2013;65(2):305310. 

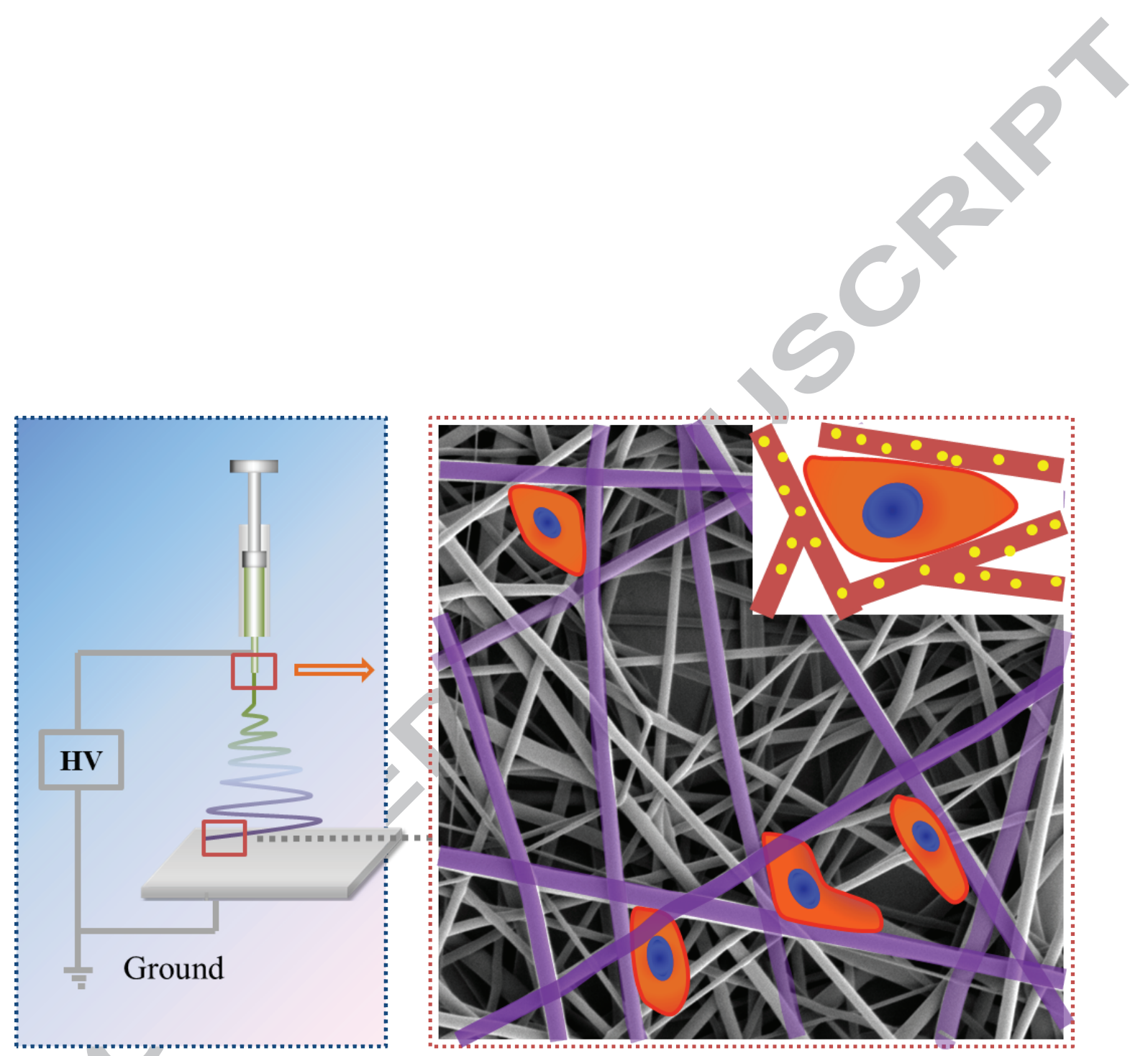